\title{
Políticas posnihilistas: exploración a partir de la idea de nihilismo en Nietzsche*
}

Postnihilistic policies: exploration from the idea of nihilism in Nietzsche

\author{
Por: Pellegrini, Brian Daniel* \\ Universidad Nacional del Nordeste \\ E-mail: briandpellegrini@gmail.com
}

Fecha de recepción: 15/03/2020

Fecha de aprobación:15/04/2020

DOI: $10.30972 /$ ach.054318

\section{Resumen}

Luego de que en 1882 Nietzsche diagnosticara que, al menos desde sus orígenes filosóficos en el Mundo Antiguo, la civilización occidental se encontraba infectada por la enfermedad del "nihilismo", la fuerza disruptiva de esa idea se ha convertido en piedra de toque de gran parte de lo hubo de ser pensado en todos los campos de la experiencia humana hasta el presente. En el terreno de la política (o de lo político, una distinción filosófica que no haremos en este trabajo) también generó diversos abordajes que van desde el intento de apropiación por parte de corrientes políticas con ideologías de lo más antagónicas hasta reflexiones que ameritan ser profundizadas ya que se trata de una de esas ideas nietzscheanas con las que el filósofo alemán abre camino a múltiples interpretaciones. El objetivo del presente trabajo es determinar si es posible superar ese horizonte nihilista trazado por Nietzsche y de si son posibles otras formas de pensar la política que podríamos dar en llamar postnihilista, es decir, que aporten marcos interpretativos por fuera de aquellas que tuvieron su origen en el paradigma racionalista de la modernidad y que se

\footnotetext{
* El presente trabajo surgen en marco de la cátedra Seminario I. Análisis de una obra filosófica del año 2019.

*Estudiantx de la Licenciatura en Filosofía de la Facultad de Humanidades (UNNE).
} 
Abril 2020.

plasmaron, por ejemplo, en instituciones como la democracia y el Estado moderno. Es decir, volver la mirada hacia el devenir conflictivo de la vida para extraer de ella elementos que permitan crear nuevas formas de pensamiento sobre la política y la sociedad.

Palabras claves: nihilismo - política - Nietzsche - vida- creación

\section{Abstract}

After Nietzsche diagnosed in 1882 that, at least from its philosophical origins in the Ancient World, Western civilization was infected by the disease of "nihilism", the disruptive force of this idea has become a touchstone for much from what had to be thought of in all fields of human experience up to the present. In the field of politics (or the political, a philosophical distinction that we will not make in this work) it also generated various approaches ranging from the attempt of appropriation by political currents with the most antagonistic ideologies to reflections that deserve to be deepened since it is one of those Nietzschean ideas with which the German philosopher opens the way to multiple interpretations. The objective of this work is to determine whether it is possible to overcome that nihilistic horizon drawn by Nietzsche and whether other ways of thinking about politics that we might call postnihilistic are possible, that is, that they provide interpretive frameworks outside of those that had their origin in the rationalist paradigm of modernity and that were reflected, for example, in institutions such as democracy and the modern state. In other words, looking back at the conflictive evolution of life to extract from it elements that allow creating new ways of thinking about politics and society.

Keywords: nihilism - politics - Nietzsche - life- creation

\section{Cómo citar este artículo:}

APA: Pellegrini, B. D. (2020). Políticas posnihilistas: exploración a partir de la idea de nihilismo en Nietzsche, Acheronta, 5, 79-95. Recuperado de: (agregar dirección web) 


\section{Introducción}

El de nihilismo es uno de los conceptos centrales del pensamiento de Nietzsche que ha abierto una multiplicidad de perspectivas de análisis y abordajes desde que fue insinuado por primera vez en La Ciencia Jovial. Partiendo de la idea de nihilismo, lo que se propone este trabajo de investigación es indagar sobre la potencialidad de un enfoque político del nihilismo en Nietzsche y sobre la posibilidad de pensar formas políticas no nihilistas o postnihilistas. Para lo cual se formulan las siguientes preguntas: ¿Pueden pensarse nuevas formas e instituciones políticas postnihilistas en base a una concepción vitalista y antimetafísica, que reconozca las relaciones de poder y la dimensión de lucha inmanente a toda formación social y su contingencia? ¿Es posible la superación del nihilismo político tal como lo problematizara Nietzsche?

\section{El nihilismo en Nietzsche}

Se podría asegurar que el de nihilismo es uno de los conceptos más potentes de toda la obra de Nietzsche. Es tan poderosa y disruptiva esa idea que después de ser formulada ningún filósofo puede permanecer indiferente. Se podrá pensar a favor o en contra de él, adherir a su idea o combatirlo, pero es indudable que hay un antes y un después de esa definición que abrió todo un horizonte del pensamiento a partir de la radical demolición de todos los valores que sustentaban al edificio de la filosofía occidental. La advertencia de Nietzsche sobre la existencia del nihilismo en muchos casos no implicó un abandono de las viejas creencias en valores trascendentes que dieran sentido a la vida del hombre, pero sí alumbraron nuevas perspectivas para lidiar con este acontecimiento. Se puede arriesgar a pensar que el filósofo alemán actuó como un médico que diagnosticó la enfermedad del mundo occidental -de hecho, muchos de sus escritos utilizan esta metáfora-, a la que emparentó con su decadencia, y que postuló que la cura la debía encontrar otro hombre, uno que fuera superación del hombre moderno, despojado de toda creencia en valores absolutos.

Antes de analizar los alcances del nihilismo político en Nietzsche, es menester trazar la genealogía del concepto de nihilismo que es, sin dudas, una de las ideas cardinales de todo el pensamiento nietzscheano. A partir del célebre aforismo 
Abril 2020.

ISSN 2344-9934

125 de La Ciencia Jovial es que el filósofo comienza a esbozar una idea que luego se volverá central en su crítica radical a la civilización y a la cultura europea de su tiempo. En aquel aforismo, conocido como "El hombre frenético", Nietzsche (1985) expone, por primera vez, la disruptiva idea de la muerte de Dios. “(...) ¡Dios ha muerto! ¡Dios permanece muerto! iY nosotros lo hemos matado! (...)" (p.115).

La interpretación más común que se le ha dado es que este "asesinato" o a esta muerte de Dios es una metáfora en la que se sintetiza el reconocimiento de la ausencia de un fundamento último, de un sentido, la falta del fin, de una verdad trascendente, de toda valoración moral. Para Nietzsche, entonces, el nihilismo (del latín: nihil, nada) se trata de una desvalorización de los valores considerados supremos y eternos que eran los pilares que sustentaban la cultura occidental en la época de la racionalidad moderna y que, a los ojos del filósofo de Rocken, se manifestaban en forma de decadencia en distintos campos como el arte, la filosofía, la moral y también en la política. Al tomar contacto con este descubrimiento, se presenta un horizonte sombrío para el hombre, acostumbrado a caminar con la creencia en un camino único y sin desvíos por lo que esta falta de sentido se torna en un costo a pagar demasiado alto, un caminar errante, sin brújula.

(...) Nos hemos curtido en la comprensión, y en ella nos hemos vuelto fríos y duros, de que en el mundo no acontece absolutamente nada de manera divina, ni tan siquiera incluso de manera racional, misericordiosa o justa de acuerdo a criterios humanos: lo sabemos, el mundo en el que vivimos es no-divino, inmoral, «inhumano» - por demasiado tiempo nos lo hemos interpretado falsa y mentirosamente, pero de acuerdo al deseo y a la voluntad de nuestra veneración, es decir, de acuerdo a una menesterosidad. ¡Pues el hombre es un animal venerador! Pero también es uno desconfiado: y que el mundo no posee el valor que nosotros habíamos creído, eso es aproximadamente lo más seguro que finalmente ha logrado atrapar nuestra desconfianza. Tanto hay de desconfianza, tanto hay de filosofía. Cuidémonos bien de decir que él es menos valioso: hoy nos parece que es como para reír cuando el hombre pretende inventar valores que debieran superar el valor del mundo real justamente de esto estamos de vuelta, como de un desmesurado extravío de la 
vanidad e irracionalidad humana, que está lejos de haber sido reconocida como tal (...) (Nietzsche, 1985, p.209).

Lo que en primera instancia se le aparece como desconcertante, incierto y desestabilizador también puede ser pensado como el liberarse de sentidos atávicos para provocar un alumbramiento de sentidos y valores nuevos, aunque reconociendo su carácter provisorio, asumiendo lo trágico como parte esencial de la vida. Y como el filósofo alemán traza un diagnóstico de época (y más que de época, civilizatorio) en la que se borra toda huella de un camino trascendente, obligaría al hombre que advirtió ese nihilismo a interrogarse sobre todo lo que consideraba respondido hasta ese momento o sobre lo que jamás consideró como un problema. Para Nietzsche (1985), la disyuntiva es "(...) «io bien abolís vuestras veneraciones o - a vosotros mismos»" (p.209).

En este punto del camino del nihilismo es que nos vamos a encontrar, por así decirlo, con una bifurcación en donde uno de los senderos conduce por lo que el autor entiende por nihilismo pasivo (reactivo) y otro, el que nos interesa para este trabajo, del nihilismo activo, que es lo que vamos a tratar de desarrollar a continuación.

\section{De los tipos de nihilismo}

Nietzsche (2006) afirma que "la desilusión sobre una supuesta finalidad del devenir es la causa del nihilismo" (p. 39). Arribamos así a esta encrucijada que nos plantea Nietzsche, llegamos al nihilismo. ¿Qué posibilidades se le presentan al hombre que ha llegado a reconocer al nihilismo como un acontecimiento? Al menos esboza dos: el nihilismo pasivo, que se presenta como un signo de debilidad, como "descenso y retroceso del poder del espíritu". En esta instancia, una vez perdida la idea de un fin impuesto por una autoridad externa, se busca una nueva autoridad para que defina una nueva meta, un nuevo telos. En la Edad Moderna, podemos pensar que esa nueva autoridad que reemplaza al Dios de la moral es la Razón, que también se expresa a través de formas políticas como el liberalismo, la democracia, el Estado moderno, que se vuelven a postular como puntos de llegada, como fines en sí mismos. Así, el nihilismo pasivo podría ser visto como una especie de resignación, de aceptación de 
Abril 2020.

que si no existe "el sentido, un sentido", la vida tampoco merece la pena. Rendirse, renunciar a la propia voluntad. Vattimo (2002) identifica al nihilismo pasivo también como reactivo y plantea que "la invención de todo tipo de disfraces, de máscaras ideológicas, es un aspecto de la actitud que se niega a reconocer que no hay significados y valores objetivos, estructuras del ser dadas, y que, por ello, se deberían crear activamente".

Pero lo que más interesa en este trabajo es pensar en la otra forma de nihilismo, el activo. ¿De qué modo se manifestaría? Como un acrecentarse del poder del espíritu, como una fuerza violentadora y destructora de viejos valores pero con una voluntad instituyente de nuevos valores, aunque esta vez transitorios, contingentes y potenciadores de la vida. Destrucción y construcción. Para Nietzsche, esta no será una tarea para el hombre moderno, demasiado ligado a la época anterior, la del nihilismo, sino que será misión de un hombre que vaya más allá del hombre moderno, un espíritu libre, un übermensch (superhombre). En este concepto de übermensch se puede advertir una concesión dialéctico teleológica, por así llamarla, en el pensamiento nietzscheano, ya que se puede interpretar como una superación del hombre moderno, un "progreso". Este espíritu libre es aquel que ya ha atravesado el umbral del nihilismo y que asume una voluntad creadora, que afirma nuevos valores a partir de sí mismo, de sus deseos e instintos. Que parte del mundo terrenal, del reconocimiento que el único mundo verdadero es el de la tierra que pisa, el de la vida que vive, que respira, que sufre y que goza. $Y$ no de un mundo inventado para escapar de éste que ya no se soporta. Que el caos y el conflicto es parte del devenir, que ya no intenta refugiarse en la creencia en un imperativo exterior, de un código moral universal que le suministre certezas sino que acepte la incertidumbre como parte del juego de la vida. Nietzsche (2006) señala:

El nihilismo es entonces la consciencia de un largo despilfarro de fuerzas, la tortura del "en vano", la inseguridad, la falta de oportunidad para rehacerse de alguna manera, de tranquilizarse todavía con cualquier cosa; la vergüenza de sí mismo, como si uno se hubiera mentido a sí mismo demasiado tiempo. (p.38 y 39) 


\section{Las manifestaciones del nihilismo}

Nietzsche se va a remontar a la Grecia Clásica para identificar al o a los precursores del nihilismo: Sócrates y su discípulo Platón. Son ellos quiénes habrían sembrado el germen de decadencia en la cultura occidental. A partir de la génesis del dualismo irreconciliable entre el alma y el cuerpo, el entronizamiento de la razón y lo inteligible (aquello que siempre es) sobre lo sensible, cambiante y en devenir, es que vislumbra el comienzo del nihilismo, de la negación de la vida, en pos depositar esperanzas en un mundo que está fuera de la vida, metafísico, donde también se incubarían los valores eternos que sostienen nuestra racionalidad, nuestro interpretar moral del mundo. La ecuación que Nietzsche demuele de manera radical es la que identifica a la razón - virtud- felicidad con la idea del Bien.

Para Nietzsche, desde que Sócrates y Platón postularon aquel mundo inteligible donde moraba la Verdad/Bien en detrimento del mundo sensible el nihilismo comenzó su despliegue a través de la civilización occidental y toda forma de organización ética o política se desarrollará bajo esta idea. Lo identifica en forma evidente en el cristianismo que también deposita su profecía escatológica de la salvación en un más allá de este mundo, en el reino de Dios. De hecho, Nietzsche (2007) llega a definir al cristianismo como "platonismo para el pueblo" (p.21).

\section{La democracia como otra forma de nihilismo}

Para pensar si son posibles modos de organización política postnihilistas, es menester repasar cuáles fueron algunos de los argumentos de Nietzsche para dinamitar todos los órdenes sociales y políticos que fueran expresión de la civilización occidental, diagnosticada de la enfermedad del nihilismo. Uno que guarda pertinencia con esta investigación es advertir algunos de los cuestionamientos del filósofo alemán a la democracia como forma de gobierno por excelencia de la modernidad occidental. Como admirador de los modelos aristocráticos, Nietzsche critica las pretensiones igualitaristas de la democracia, en las que percibe una continuidad de la moral de rebaño que denuncia en el cristianismo. Así, Nietzsche (2007) afirma que “(...) el movimiento democrático constituye la herencia del movimiento cristiano" (p.145). 
Abril 2020.

ISSN 2344-9934

Más que a la democracia como forma de gobierno, el autor la identifica con cierto clima cultural en el que predomina la idea de una igualación de los hombres lo que juzga como un sinónimo de mediocridad, un alzarse contra las leyes naturales según las cuales algunos hombres están dotados para el mando y otros para obedecer. Por eso se manifiesta abiertamente contra las ideas de "Libertad, igualdad y fraternidad" de la Revolución Francesa a las que identifica con la decadencia, con el resentimiento de las clases débiles que quieren igualarse como una suerte de venganza contra los dominadores, a un repudio de las diferencias. Sin dudas, se trata de una idea disruptiva de la democracia pero que no por eso debemos asumir en su literalidad. En ese sentido, Nietzsche (2007) afirma:

Nosotros los que somos de otra fe, nosotros los que consideramos el movimiento democrático no meramente como una forma de decadencia de la organización política, sino como forma de decadencia, esto es, de empequeñecimiento del hombre, como su mediocrización y como su rebajamiento de valor" (p.146,147).

Desde un enfoque que posiblemente no sería el pretendido por Nietzsche, no se estaría lejos de pensar en que aquellos ideales proclamados por la Revolución Francesa fueron, en realidad, una promesa nunca concretada. De hecho, hay que recordar la valoración que el filósofo alemán hacía de Voltaire en detrimento de Rousseau. Esa promesa revolucionaria rousseuaniana le resultaba impracticable.

El pensamiento nietzscheano, al hacer implosionar los pilares de la racionalidad en los que se sustentan todas las instituciones de la modernidad occidental, habilitaría, en realidad, la posibilidad de un enfoque más realista sobre los alcances de lo político, hasta ahora demasiado ligados al nihilismo, que lo interpreta a partir de la idea del orden frente al conflicto, frente a la tensión y la lucha permanente por el poder que son esenciales de lo político, una dimensión que puede quedar en un segundo plano si se sigue identificando a la política con la idea de Bien.

Pero otro plano en que se puede comprender la crítica de Nietzsche a la democracia es en el de la pretensión de presentarse como la instancia última de 
organización de una comunidad política y de no asumirse en su provisionalidad, en su contingencia. Aquí podemos apelar a su cuestionamiento a la falta de sentido histórico de los filósofos, de pensar a un hombre eterno, que siempre es, en lugar de concebirlo en devenir. Y esta es una idea que atraviesa también esta crítica a las formas políticas de la modernidad. Sostiene Nietzsche (2001): “(...) No hay datos eternos, lo mismo que no hay verdades absolutas" (p.44). ¿Es que acaso no se puede cuestionar, hoy por hoy, a las actuales democracias liberales (democracia y liberalismo no son dos términos que siempre hayan convivido) realmente existentes subordinadas a la lógica cada vez más excluyente del mercado? ¿Eso nos haría sospechosos de querer quebrantar un supuesto orden incuestionable? En este sentido, lo plantea Diego Paredes (2009): "Si la democracia, al igual que la metafísica, carece de sentido histórico, su desconocimiento del devenir le impedirá examinar sus propios condicionamientos y, de este modo, le será vetada toda variabilidad, toda posibilidad de cambio".

\section{El Estado moderno como forma de nihilismo}

Así como denuncia las sombras de la razón en el edificio democrático, Nietzsche también va a enfocar su tarea de demolición del Estado moderno. Mejor sería expresarlo de esta manera: avizora que la misma democracia, entendida como soberanía popular, va a destruir al Estado moderno. Según sostiene Vita (2009), para Nietzsche "El Estado no contribuye al desarrollo de la vida sino todo lo contrario. El hombre no sólo no se desarrolla en el ámbito del Estado sino que además se vulgariza, se angustia”. (p. 221)

En este sentido, lo que plantea es que el gobierno democrático mantuvo desde siempre una alianza con la religión, es decir que se fundamentó en la creencia en un origen divino de las cosas políticas por lo que llegó a la conclusión de que la muerte de la religión -y esto es parte del nihilismo- también llevaría con ella el fin del Estado moderno. ¿Por qué? Para Nietzsche, a partir de la consolidación de la democracia moderna como forma de gobierno se va a producir una transformación en los criterios de legitimidad que durante las monarquías todavía se asumía derivada de Dios, a través de la religión. Con la soberanía del pueblo, el Estado no va a prescindir 
Abril 2020.

ISSN 2344-9934

de su alianza con la religión porque será un instrumento que le permite detentar autoridad y disuadir cualquier intento de rebelión y alteración del orden. Sin embargo, esa utilización táctica de la religión por parte del Estado va a contener su propia destrucción cuando la religión se convierta en algo privado a partir del desarrollo de la propia lógica democrática con la creciente diversidad de opiniones en materia religiosa.

Como puede apreciarse, aunque a veces parezca lo contrario, a lo largo de su obra el filósofo de Rocken no mantiene una opinión unívoca sobre las instituciones que en algún momento llega a criticar en forma demoledora. Incluso, les reconoce méritos, pero lo que nunca vamos a encontrar es que considere que alguna institución deba permanecer o que sea algún modelo a ser imitado.

Nietzsche (2001) define a la democracia moderna como "la forma histórica de la decadencia del Estado" (p.228). Sin embargo, no considera que este derrumbe del Estado moderno implique volver al caos sino que vislumbra que una nueva forma política, un nuevo orden "triunfará sobre el Estado". Es aquí en donde se puede advertir, nuevamente, que las críticas de Nietzsche apuntan más a describir como nihilistas aquellas ideas e instituciones políticas de la modernidad que se conciben a sí mismas en términos necesarios, permanentes, eternos, sin asumirse como parte de una permanente lucha entre una multiplicidad de fuerzas que se enfrentan y que transitoriamente se manifiestan en determinados órdenes políticos y sociales contingentes, provisorios, y que no pueden ser estabilizadas porque están en constante devenir.

\section{¿Entonces quién crea los nuevos valores postnihilistas?}

Una vez explorados algunas de las principales críticas de Nietzsche a las ideas y formas nihilistas de organización política modernas, es menester analizar qué entendía el filósofo de Rocken por la creación de nuevos valores y en qué se debían sustentar estas formulaciones y sí, en ese camino, se puede pensar en ordenamientos (así en plural) posnihilistas. Hasta aquí hemos advertido las demoledoras críticas que Nietzsche prodigaba a todas las ideas, pensamientos e instituciones que planteaban 
una interpretación del mundo en donde continuaban operando los dualismos desde Sócrates/Platón, donde uno primaba absolutamente sobre el otro: el alma sobre el cuerpo, lo inteligible sobre lo sensible, lo eterno sobre el devenir, la razón sobre los instintos.

En sus últimos escritos, que fueron publicados forma póstuma, Nietzsche (2006) va a afirmar que el nihilismo es "solamente un estado de transición". Sin embargo, es una transición en una temporalidad distinta a la pensaba en la modernidad, al tiempo lineal. Es decir, sería una transición en el marco del devenir sin un telos o un sentido final. En este sentido, la superación del nihilismo no va a requerir que estos espíritus libres o el superhombre inviertan ese esquema de valoración dualista, sino que tengan la voluntad de destruir la estructura dualista para crear e imponer otros valores que no tengan más fundamento que la propia vida y la voluntad de este hombre postnihilista. ¿Pero el espíritu libre o el superhombre siguen siendo nihilistas activos? Sí y no. Se puede pensar que ambos son un puente entre el viejo esquema dualista del cual el nihilismo era la manifestación más evidente y un nuevo esquema de valoración que se expresaría a partir de una tabula rasa siempre abierta, flexible, deviniente. Nietzsche afirma que la creencia siempre se ha preferido como sustituto a la falta de voluntad y plantea que, justamente, ese tipo de inclinación es la que ha alimentado al nihilismo. Una certeza que nos sea impuesta, un deber, un terreno sólido bajo nuestros pies, antes que aventurarnos al riesgo de asumir nuestra propia libertad de crear. Creer antes que crear. Así, sostiene Nietzsche (1985):

(...) sería pensable un placer y una fuerza de la autodeterminación, una libertad de la voluntad, en la que un espíritu dice adiós a toda creencia, a todo deseo por la certeza, ejercitado, como está, para poder sostenerse sobre cuerdas flojas y débiles posibilidades y a bailar incluso al borde de abismos. Tal espíritu sería el espíritu libre par excellence [por excelencia] (p. 348).

En este punto, interesa rescatar al filósofo italiano Gianni Vattimo (2004) quién propone pensar al nihilismo en términos de emancipación. Por esto se entiende "un proceso de liberación de vínculos dirigidos a una mayor libertad, autonomía, posibilidad de elección". Esto proceso sería desencadenado por el nihilismo al que el 
Abril 2020.

ISSN 2344-9934

autor identifica con la hermenéutica. Para él, una vez disuelto todo fundamento último, sólo quedaría reconocer la provisionalidad de cualquier idea de "verdad", que no vendría impuesta desde afuera sino que sería producto de una especie de acuerdo entre los hombres, un pluralismo. Para referirse a este proceso, el italiano postula la idea de un "pensamiento débil". Vattimo (2004) lo plantea así:

(...) La disolución de los fundamentos (en la que se puede reconocer también el tránsito de la modernidad a la posmodernidad) es lo que libera, una vez más, con una profunda referencia a la expresión evangélica según la cual 'la verdad os hará libres'. Esto no significa: os liberará saber cómo están las cosas 'realmente' (...) sino: es verdad sólo lo que os libera y ante todo por tanto el descubrimiento de que no hay fundamentos últimos ante los cuales nuestra libertad deba detenerse, como, por el contrario, siempre han pretendido hacernos creer las autoridades de todo tipo que querían imponerse en nombre de estas estructuras últimas. (p.10).

Si bien coincidimos en interpretar al nihilismo en términos de liberación de imposiciones metafísicas y universales, como lo hace el filósofo italiano, no compartimos su optimismo en que a partir de la toma de conciencia del nihilismo ya se estaría en condiciones de pensar en términos emancipatorios, al menos no en el sentido de grandes cambios sociales como lo da a entender o que encarne en lo que llama provocadoramente el "ultrahombre de masas" que sería un nuevo sujeto "que no destaca sobre el fondo de una sociedad de esclavos, sino que vive en una sociedad de iguales" (p.204).

Llegados a esta altura de la investigación, es menester incorporar una estimulante formulación de la filósofa argentina Mónica Cragnolini, quién, en términos generales, coincide con ese sesgo liberador del nihilismo que postula Vattimo, pero que incorpora la idea de una "razón imaginativa" para superar el momento del nihilismo pasivo, para ingresar en un terreno de lo que podríamos llamar postnihilismo, en tanto superación o más allá del nihilismo. Para la filósofa, esta "razón imaginativa" elude los pensamientos extremos y busca conjugarlos (la pura formalidad y la pura multiplicidad) en soluciones provisionales, pero a partir de la propia voluntad, del riesgo de ensayar y errar, de asumir el carácter trágico de la existencia, de la falta 
de una Verdad suprema a la cual haya que Ilegar. En ese sentido, Cragnolini apunta a que esta "razón imaginativa" se exprese en un hombre posnihilista a través de la creación de sentidos siempre transitorios, desde una postura perspectivística, que respeta la diferencia, y que a partir de asumir la condición de una voluntad interpretante, se transforme en un "filósofo artista" o en "el niño que juega el juego del mundo". Otra vez, el énfasis estará en la creación, en la actividad, en la voluntad afirmativa.

\section{Los postnihilismos}

A partir de estos desarrollos teóricos es que podemos pasar al campo político y social propiamente dicho. Primero debemos aclarar que un análisis más riguroso sobre este tipo de organizaciones demandaría una investigación mucho más exhaustiva que dé cuenta de sus especificidades, de sus alcances y limitaciones. Pero a los efectos de este ensayo exploratorio, podemos advertir que movimientos como los ecologistas, feministas (que no podemos llamar "nuevos" porque llevan casi medio siglo de existencia cada uno) o de personas trans entendemos que entrarían dentro de lo que a grandes rasgos podríamos denominar como formas de organización posnihilistas. ¿Por qué? En el primer caso, se trataría de una nueva valoración de la relación del hombre con la naturaleza, de rescatar otro tipo de cosmovisiones en su relación con la tierra, que hoy sigue siendo avasallada por el dominio de la razón tecnocientífica que destruye todo lo que encuentra en su camino con el único objetivo de mercantilizarlo todo, prolongando la etapa negativa del nihilismo hasta alcanzar diagnósticos aún más sombríos de los que avizoraba Nietzsche hace dos siglos atrás. Esos movimientos ecologistas (los mencionamos en plural porque no se reducen a lo uno) están suponiendo un nuevo tipo de hombre, y un nuevo tipo de relación con la naturaleza y con los otros.

Por el lado de los feminismos, de un desarrollo exponencial en la Argentina de los últimos años, se percibe allí una nueva valoración de la relación de las mujeres con sus propios cuerpos, contra los deberes y funciones que se les asignarían por 
Abril 2020.

ISSN 2344-9934

"naturaleza", nunca equiparables al hombre. ¿No estarían, estos movimientos feministas, tratando de dinamitar al nihilismo representado por el patriarcado?

En el caso de las luchas de los movimientos de personas trans, también hay allí nuevas valoraciones que ponen en jaque viejas distinciones absolutas, en este caso a la idea de identidad y también de la determinación biológica, entendiendo a la identidad sexual como una voluntad no definida por instancias externas.

Este tipo de movimientos y organizaciones pueden ser consideramos posnihilistas, en tanto se admitan con sentidos y valores plurales, contingentes, y no vuelvan a apuntar a imponerse como un orden único. Pero también existe la posibilidad que devengan lo contrario, es decir, que se orienten hacia una radicalización que intente imponerse a otros grupos. Escribe Nietzsche (1985): "Los que somos diferentes somos la excepción y el peligro -ieternamente requerimos defendernos! - Y bien, realmente cabe decir algo a favor de la excepción, siempre y cuando nunca quiera convertirse en regla". (p.76)

En ningún tramo de este análisis mencionamos la palabra "derechos" porque entendemos que abordarlo desde esa perspectiva sería reducir a estos movimientos a sólo una de sus manifestaciones. El éxito que pudiera tener el reconocimiento de derechos ambientales, de las mujeres o de las personas trans no debe hacer perder de vista la condición trágica de la vida donde ya no tenemos garantías de que las conquistas serán permanentes, ni aún las expresadas en forma de derechos.

En el campo político, por tanto, traspasar el umbral del nihilismo implicaría el reconocimiento de la posibilidad de desarrollar nuevas formas de pensamiento y de organización política que escapen a lo que hasta el momento la racionalidad occidental nos ha ofrecido como únicas variantes. Puede, asimismo, funcionar como antídoto a la aporía de una crítica que ha perdido la capacidad de imaginar otros modos políticos, otras formas éticas. 


\section{Conclusión}

En ese escrito póstumo que fue La Voluntad de Poder (2006), Nietzsche profetizaba: "Lo que cuento es la historia de los dos próximos siglos. Describe lo que sucederá, lo que no podrá suceder de otra manera: la llegada del nihilismo" (p.31). ¿Cómo concluir, entonces, un trabajo sobre un autor que se ha caracterizado por una forma de pensamiento abierto, liberador, que no busca cristalizarse en algo que podamos llamar "conclusión"? Sobre todo, si tenemos en cuenta que lo más potente y disruptivo del pensamiento de Nietzsche es su faceta de la crítica, que es sobre que intentamos dar cuenta en este trabajo. En esta etapa el filósofo alemán está pariendo armas para la crítica, para demoler certezas y formular interrogantes y no para indicar algún tipo de curso de acción deseable. Nietzsche asume como misión poner patas para arriba todos los "para qué" de la cultura occidental, considerando que estaban viciados de nihilismo desde el inicio, desde que Sócrates/Platón postularon que había dos mundos y le negaron valor al único que Nietzsche consideraba verdadero.

No obstante, una vez planteada esta aclaración podemos ensayar una conclusión o, aún mejor, una serie de conclusiones provisorias. Abordamos en este trabajo el concepto de nihilismo y las que serían sus manifestaciones más notables para Nietzsche, así como también lo interpretamos desde un punto de vista político.

Lo primero que se puede plantear es que ese horizonte de nihilismo que Nietzsche vislumbrara hace casi 140 años (La Ciencia Jovial fue editada originalmente en 1882) se mantiene vigente. Y aquí estaría la "transición" del nihilismo que el filósofo reconoció. Aún más, la actualidad de la civilización occidental que hoy podemos pensar como habiendo colonizado a todas las demás civilizaciones, no haría más que confirmar el vaticinio nietzscheano. En distintos ámbitos de la vida siguen imponiéndose nihilismos de diversa naturaleza. No podemos menos que advertir que la crítica radical a la que somete Nietzsche a la civilización occidental en tanto despliegue del nihilismo prefiguraron muchas de las catástrofes que después acontecieron.

A pesar de la muerte de Dios aún el hombre sigue venerando sus sombras, alimentando fantasmas que se resisten a desaparecer. ¿Por qué? Porque se siguen 
Abril 2020.

buscando creencias, certezas últimas, y no asumimos de una vez nuestra esencia vital en una forma activa: nuestra voluntad de poder. Seguimos anhelando sentidos absolutos, sin reconocer la precariedad de cualquier valor que intente ordenar el caos infinito de la vida. Dentro de ese espíritu de época, se pueden advertir distintos movimientos que deciden asumir la naturaleza de la voluntad, ejercerla procurando estilos de vida y formas de organización política y social postnihilistas. Una de sus principales características es que parten de una base en la que deben convivir con la resistencia a abandonar aquellos viejos valores absolutos pero sin embargo se definen por esa apuesta creativa de afirmar nuevos sentidos, de construir órdenes provisionales, contingentes.

Así, mientras seguimos gobernados por una racionalidad global, totalizante, que se nos impone en forma nihilista como nuevo orden fuertemente moral y maniqueo (del bien contra el mal), siempre queda abierta la posibilidad de pensar críticamente, de poder reconocer los límites de esa racionalidad para ponerla en cuestión y de reconocer formas de organización éticas y políticas que escapen a una pretensión de universalidad. Apelar a aquellas ideas que Nietzsche vislumbró en los albores de la edad moderna pueden permitir volver a desenmascarar a las formas nihilistas que nunca dejaron de manifestarse, aceptando que se trata en definitiva de una batalla de la que no podemos conocer el desenlace (si es que hay desenlace y no eterno retorno) sólo que debemos reconocernos en nuestra voluntad de afirmar otro modo de pensar, de organizarnos políticamente, valorando la tragicidad y el devenir de la vida. Aunque moribundos desde hace tiempo, los valores trascedentes que dieron sentido a la civilización occidental se resisten a morir y los otros tampoco terminan por nacer, aunque muchos ya estén comprometidos en alumbrarlos.

Para cerrar esta conclusión, elijo un aforismo de la Ciencia Jovial en el que Nietzsche describe el ánimo de quienes han asumido la muerte de Dios y sobre la potencialidad que ese acontecimiento significa para los hombres. Sostiene el filósofo de Rocken que:

De hecho, nosotros, filósofos y "espíritus libres», ante la noticia de que el "viejo Dios ha muerto», nos sentimos como iluminados por una nueva aurora: ante 
eso nuestro corazón rebosa de agradecimiento, asombro, presentimiento, expectación -finalmente el horizonte se nos aparece libre de nuevo, aun cuando no esté despejado; finalmente podrán zarpar de nuevo nuestros barcos, zarpar hacia cualquier peligro, de nuevo se permite cualquier riesgo de los que conocen; el mar, nuestro mar, yace abierto allí de nuevo, tal vez nunca hubo antes un «mar tan abierto» (p.204).

\section{Referencias bibliográficas}

Cragnolini, M. (2003). Nietzsche, camino y demora. Buenos Aires: Editorial Biblos.

Nietzsche, F. (1985). La Ciencia Jovial. La Gaya scienza. (J.Jara, Trad.). Caracas: Monte Avila Editores.

Nietzsche, F. (2007). Más allá del bien y del mal. (A.Sánchez Pascual, Trad.). Madrid: Alianza Editorial.

Nietzsche, F. (2006). Voluntad de poder. (A. Froufe, Trad.). Madrid: Editorial Edaf.

Paredes Goicoechea, D. (2009), La crítica de Nietzsche a la democracia. Bogotá:

Facultad de Ciencias Humanas de la Universidad Nacional de Colombia.

Vattimo, G. (2004). Nihilismo y emancipación. Barcelona: Paidos.

Vita, L. (2009). La crítica de Nietzsche al Estado moderno. Lecciones y Ensayos, Nro. 86, p. $213-233$ 